\title{
Design of Coplanar Dipole Antenna with Inverted-H Slot for 0.9/1.575/2.0/2.4/2.45/5.0 GHz Applications
}

\author{
Yuh-Yih Lu*, Enfu Lin \\ Email address: \\ yylu@must.edu.tw (Yuh-Yih Lu) \\ ${ }^{*}$ Corresponding author
}

Department of Electrical Engineering, Minghsin University of Science and Technology, Hsinchu, Taiwan

\section{To cite this article:}

Yuh-Yih Lu, Enfu Lin. Design of Coplanar Dipole Antenna with Inverted-H Slot for 0.9/1.575/2.0/2.4/2.45/5.0 GHz Applications. Journal of Electrical and Electronic Engineering. Vol. 5, No. 2, 2017, pp. 38-47. doi: 10.11648/j.jeee.20170502.13

Received: March 14, 2017; Accepted: March 31, 2017; Published: April 6, 2017

\begin{abstract}
A coplanar symmetric dipole slot antenna with inverted-H slot is proposed for 0.9/1.575/2.0/2.4/2.45/5.0 GHz wireless communication applications. The inverted-H slot is etched on the metallic layer of a single sided printed circuit board to form the coplanar dipole slot antenna. The dimensions of inverted-H slot are changed to design and fabricate the antenna which can be operated at 0.9/1.575/2.0/2.4/2.45/5.0 GHz successfully. We use IE3D software to design this dipole slot antenna and choose the better parameters to manufacture the proposed antenna. The influences of slot dimension parameters of the proposed antenna on resonant frequency, input reflection coefficient expressed in decibel and impedance bandwidth are described. The proposed antenna with the volume of $123 \mathrm{~mm} \times 31 \mathrm{~mm} \times 1.6 \mathrm{~mm}$ has been fabricated. The measured result shows that the proposed antenna can be successfully operated at 0.9/1.575/2.0/2.4/2.45/5.0 GHz.
\end{abstract}

Keywords: Coplanar, Dipole Antenna, Inverted-H, Slot

\section{Introduction}

It is well known that compact size, lower cost and easy fabrication are important factors to design antenna that can be used in wireless commercial products. Planar antennas possess these attractive features. Hence, many articles about planar antennas had been studied and widely used in Global positioning System (GPS), Radio Frequency Identification (RFID), and Wireless Local Area Network (WLAN) systems [1-9]. Pokemon Go is the popular game in the world. Pokemon Go for cellular phone devices let user travel between the real and virtual world of pokemon. This game platform uses real locations to encourage players to discover Pokemon. The hot game of Pokemon Go pushes the world come to the applications with location and wireless communication. Hence, smart devices with GPS and WiFi functions are the trend of the world. Bandwidth enhancement in antenna design can meet the need for increasing the data transfer. This requirement can be achieved using the slot antenna techniques [10-11]. Today, wireless communication devices relating to the field of the internet of things are developed rapidly. These information devices should be capable of large bandwidth and operating at multiple frequency bands. Therefore, researches have been reported for multi-band planar antenna [12-14].

In this study, a simple coplanar dipole antenna with inverted-H slot is proposed. The operating frequency band and impedance bandwidth are obtained from IE3D simulations. The structure parameters of the inverted-H slot control the operating frequency band of the coplanar dipole antenna. The coplanar dipole slot antenna designed with inverted-H slot excites the resonant frequency that can be used for 802.11ah standard (902-928 MHz), GPS (1575 MHz), TD-SCDMA (2.01-2.025GHz), WLAN (2.4-2.484GHz), RFID (2.45GHz), public safety application $(4.94-4.99 \mathrm{GHz})$, and $802.11 \mathrm{a}$ standard $(5.15-5.35 \mathrm{GHz})$. The suitable geometric parameters of the inverted-H slot are chosen to fabricate the proposed antenna. Therefore, a simple coplanar symmetric dipole slot antenna with the size of $123 \mathrm{~mm} \times 31 \mathrm{~mm} \times 1.6 \mathrm{~mm}$ is presented in this paper. The proposed antenna can be built on a single sided printed circuit board. The single metal layer structure is suitable for mass production and reduces the manufacturing cost. The configuration of the proposed coplanar dipole antenna is presented in section 2 while the simulation and experimental 
results including discussion are described in section 3 and 4.

\section{Antenna Design}

The proposed coplanar dipole slot antenna with inverted-H slot structure is printed on a single metallic layer of FR4 dielectric substrate which has permittivity of 4.4 and thickness of $1.6 \mathrm{~mm}$. The configuration of this proposed antenna is depicted in Figure 1. In this figure, the symmetric inverted-H slot is etched on the metallic layer to create the operating frequency bands.
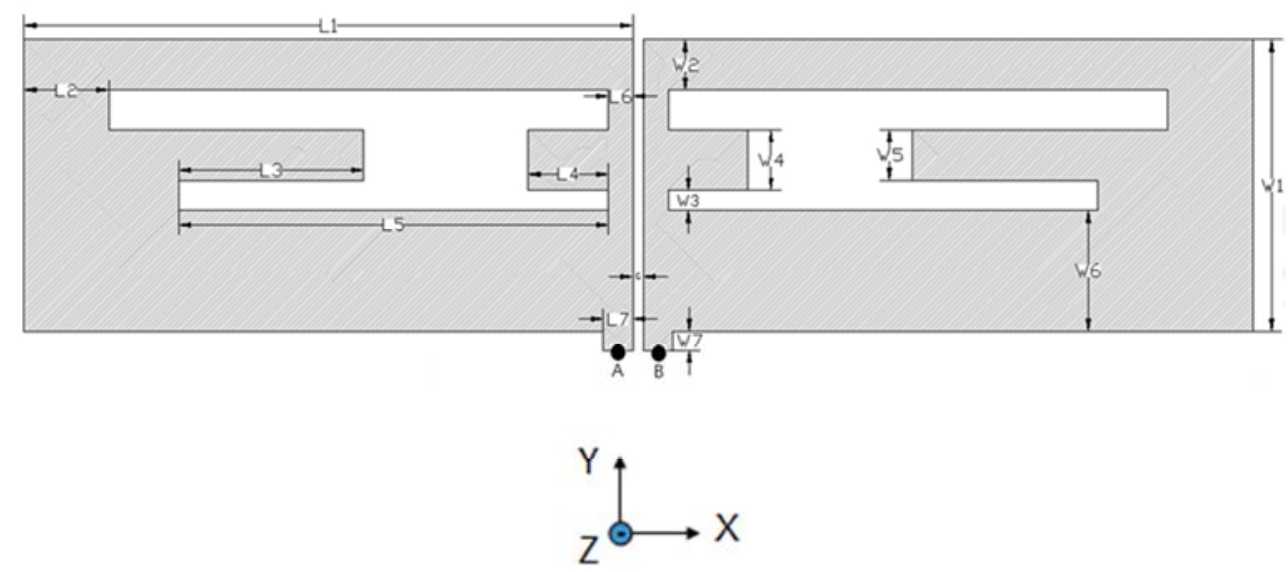

Figure 1. Geometry of the proposed coplanar dipole antenna with inverted-H slot.

We adjust the inverted-H slot structure parameters L2 and W2 to observe the variations with respect to resonant frequency $\left(\mathrm{f}_{0}\right)$, input reflection coefficient expressed in decibel $\left(\mathrm{S}_{11}\right)$, lower frequency band limit $\left(\mathrm{f}_{1}\right)$, upper frequency band limit $\left(\mathrm{f}_{2}\right)$, and impedance bandwidth $(\mathrm{BW})$ of the proposed antennas. The dimension parameters of the proposed antenna shown in Figure 1 are listed below: $\mathrm{W} 1=29 \mathrm{~mm}, \quad \mathrm{~W} 3=2.0 \mathrm{~mm}, \quad \mathrm{~W} 4=6.0 \mathrm{~mm}, \quad \mathrm{~W} 5=5.0 \mathrm{~mm}$, $\mathrm{W} 6=12.0 \mathrm{~mm}, \mathrm{~W} 7=2.0 \mathrm{~mm}, \mathrm{G}=1 \mathrm{~mm}, \mathrm{~L} 1=61 \mathrm{~mm}, \mathrm{~L} 3=18.5 \mathrm{~mm}$, $\mathrm{L} 4=8.0 \mathrm{~mm}, \mathrm{~L} 5=43 \mathrm{~mm}, \mathrm{~L} 6=2.5 \mathrm{~mm}$, and $\mathrm{L} 7=3.0 \mathrm{~mm}$. Points A and $\mathrm{B}$ are the feeding points of the coplanar dipole slot antenna. The $50 \mathrm{ohm}$ coaxial connector was adopted for testing.

\section{The Simulations}

We adopted various dimension parameters L2 and W2 shown in Figure 1 of the coplanar symmetric dipole slot antenna to observe the characteristics of the proposed antenna. The numerical simulation and analysis for the proposed antennas are performed using IE3D simulation software. The simulated curves of $S_{11}$ against frequency for varying the inverted-H slot parameter L2 of the proposed antenna with $\mathrm{W} 2=5 \mathrm{~mm}$ are shown in Figure 2. The simulated results including resonant frequency $\left(\mathrm{f}_{0}\right)$, input reflection coefficient expressed in decibel $\left(S_{11}\right)$, lower frequency band limit $\left(f_{1}\right)$, upper frequency band limit $\left(\mathrm{f}_{2}\right)$, and impedance bandwidth (BW) are listed in Table 1.

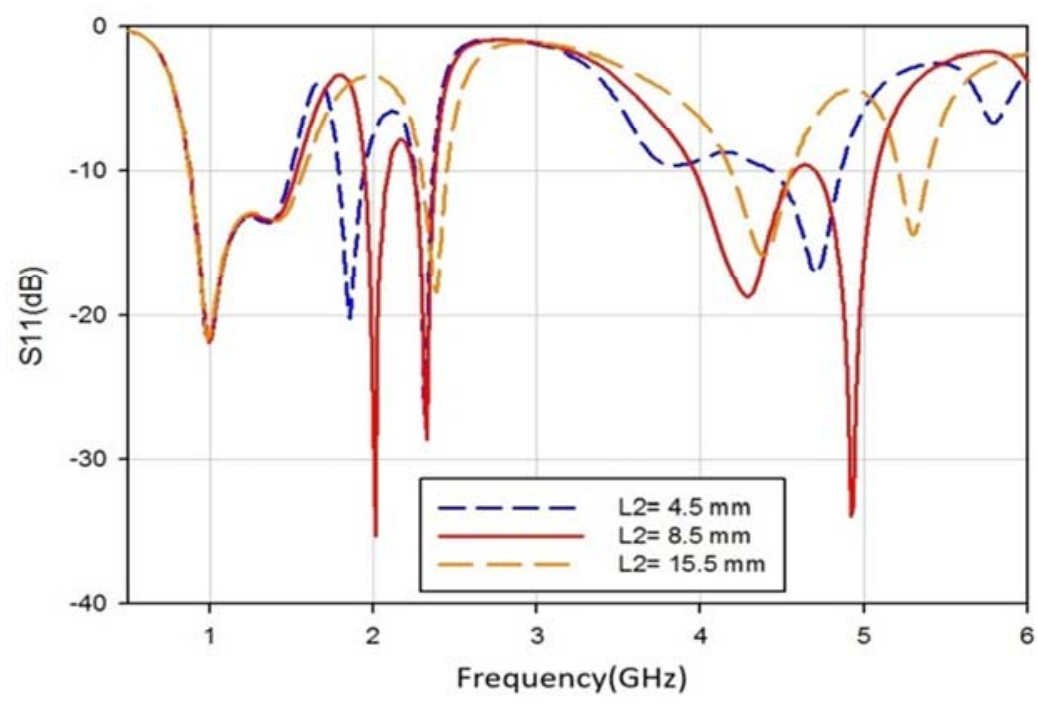

Figure 2. Simulated curves of $S_{11}$ against frequency for varying $L 2$ of the proposed dipole slot antenna with $W 2=5 \mathrm{~mm}$. 
From Figure 2 and Table 1, four or five operating frequency bands are observed with changing structure parameter L2. The lowest resonant frequency is nearly unchanged but the higher resonant frequency is slightly shifted to higher frequency with increasing the value of L2. At the lowest frequency band $(0.87-1.57 \mathrm{GHz})$, the impedance bandwidth is slightly increased with increasing L2. The resonant frequency shifts to higher frequency with increasing the value of L2 at the middle frequency bands $(1.78-2.45 \mathrm{GHz})$. At higher frequency bands (3.96-5.39), larger value of L2 will excite two valuable frequency bands. The inverted-H slot with $\mathrm{L} 2=8.5 \mathrm{~mm}$ exhibits the better characteristics of the proposed antenna which can operate at $5 \mathrm{GHz}$ band. The simulated curves of $\mathrm{S}_{11}$ against frequency for varying another slot parameter $\mathrm{W} 2$ of the proposed antenna with $\mathrm{L} 2=8.5 \mathrm{~mm}$ is shown in Figure 3. The simulated results from Figure 3 are also listed in Table 2.

From Figure 3 and Table 2, three or five operating frequency bands are observed with changing inverted-H slot parameter W2. The lowest resonant frequency and the highest resonant frequency are slightly shifted to higher frequency with increasing the value of W2. Due to impedance mismatch, single band splits into dual band at the middle frequency bands $(1.95-2.43 \mathrm{GHz})$ and higher frequency bands $(3.93-5.07 \mathrm{GHz})$ with increasing the value of $\mathrm{W} 2$.

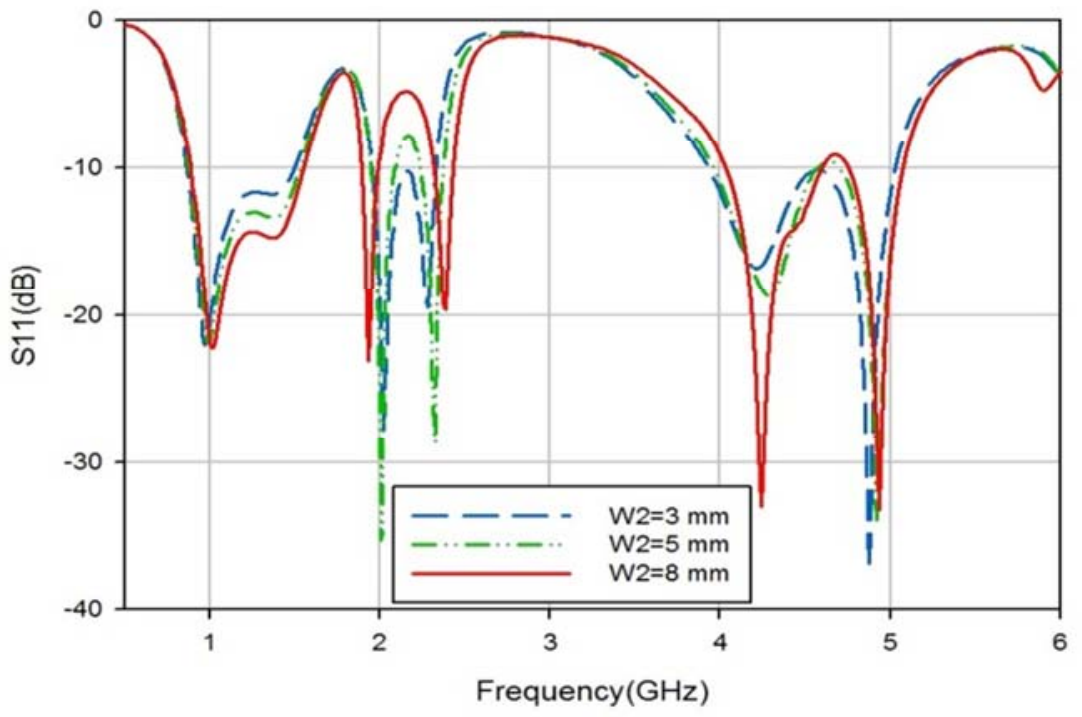

Figure 3. Simulated curves of $S_{11}$ against frequency for varying $W 2$ of the proposed dipole slot antenna with $L 2=8.5 \mathrm{~mm}$.

Table 1. Simulated results of the proposed dipole slot antenna with $W 2=5 \mathrm{~mm}$.

\begin{tabular}{lllll}
\hline $\mathbf{L 2}$ & $\mathbf{f}_{\mathbf{0}}$ & $\mathbf{S}_{\mathbf{1 1}}$ & $\mathbf{f}_{\mathbf{1}}, \mathbf{f}_{\mathbf{2}}$ & $\mathbf{B W}$ \\
\hline $\mathbf{( m m})$ & $(\mathbf{G H z})$ & $\mathbf{( d B )}$ & $\mathbf{( G H z})$ & $\mathbf{( G H z )}$ \\
\hline & 0.99 & -22.02 & $0.87,1.49$ & 0.62 \\
& 1.85 & -20.09 & $1.78,1.94$ & 0.16 \\
4.5 & 2.30 & -26.44 & $2.25,2.36$ & 0.11 \\
& 4.70 & -17.10 & $4.43,4.85$ & 0.42 \\
& 0.99 & -21.90 & $0.87,1.53$ & 0.66 \\
& 2.00 & -34.56 & $1.94,2.09$ & 0.15 \\
8.5 & 2.31 & -27.16 & $2.24,2.37$ & 0.13 \\
& 4.29 & -18.72 & $3.96,4.57$ & 0.61 \\
& 4.92 & -33.47 & $4.69,5.07$ & 0.38 \\
& 0.99 & -21.68 & $0.87,1.57$ & 0.70 \\
& 2.38 & -18.38 & $2.29,2.45$ & 0.16 \\
& 4.38 & -15.85 & $4.18,4.56$ & 0.38 \\
& 5.30 & -14.38 & $5.21,5.39$ & 0.18 \\
\hline
\end{tabular}

The inverted-H slot with W2 equals to $8.5 \mathrm{~mm}$ and $15.5 \mathrm{~mm}$ exhibit more operating band characteristics of the proposed antenna. In other word, the smaller size of inverted-H slot results in impedance mismatch. At the middle frequency bands $(1.95-2.43 \mathrm{GHz})$, the upper frequency band limit $\left(\mathrm{f}_{2}\right)$ of the proposed dipole slot antenna with $\mathrm{L} 2=8.5 \mathrm{~mm}$ increases with increasing the value of W2. While the upper frequency band limit $\left(f_{2}\right)$ of these antennas is nearly unchanged with increasing the value of W2 at higher frequency band (3.93-5.07GHz). Therefore, carefully adjusting the inverted-H slot structure parameters L2 and W2 of the proposed antenna is very important to design the coplanar dipole slot antenna that can be used at $0.9 / 1.575 / 2.0 / 2.4 / 2.45 / 5.0 \mathrm{GHz}$.

Table 2. Simulated results of the proposed dipole slot antenna with $L 2=8.5 \mathrm{~mm}$.

\begin{tabular}{lllll}
\hline $\mathbf{W} 2$ & $\mathbf{f}_{\mathbf{0}}$ & $\mathbf{S}_{\mathbf{1 1}}$ & $\mathbf{f}_{\mathbf{1}}, \mathbf{f}_{\mathbf{2}}$ & $\mathbf{B W}$ \\
\hline $\mathbf{( m m})$ & $(\mathbf{G H z})$ & $\mathbf{( d B )}$ & $\mathbf{( G H z})$ & $\mathbf{( G H z )}$ \\
\hline \multirow{3}{*}{3} & 0.97 & -21.95 & $0.86,1.50$ & 0.64 \\
& 2.02 & -26.97 & $1.95,2.33$ & 0.38 \\
& 4.87 & -35.99 & $3.93,5.03$ & 1.10 \\
& 0.99 & -21.90 & $0.87,1.53$ & 0.66 \\
5 & 2.00 & -34.56 & $1.94,2.09$ & 0.15 \\
& 2.31 & -27.16 & $2.24,2.37$ & 0.13 \\
& 4.29 & -18.72 & $3.96,4.57$ & 0.61 \\
& 4.92 & -33.47 & $4.69,5.07$ & 0.38 \\
& 1.01 & -22.18 & $0.88,1.55$ & 0.67 \\
& 1.93 & -22.92 & $1.89,1.99$ & 0.10 \\
& 2.38 & -19.55 & $2.31,2.43$ & 0.12 \\
& 4.24 & -32.27 & $4.03,4.59$ & 0.56 \\
& 4.93 & -32.89 & $4.75,5.07$ & 0.32 \\
\hline
\end{tabular}




\section{Experimental Results and Discussion}

Figure 4 shows the photography of fabricated traditional type coplanar dipole antenna without slot. The simulation and measurement results of this antenna are depicted in Figure 5 and listed in Table 3 including $\mathrm{f}_{0}, \mathrm{~S}_{11}, \mathrm{f}_{1}, \mathrm{f}_{2}$, and BW.

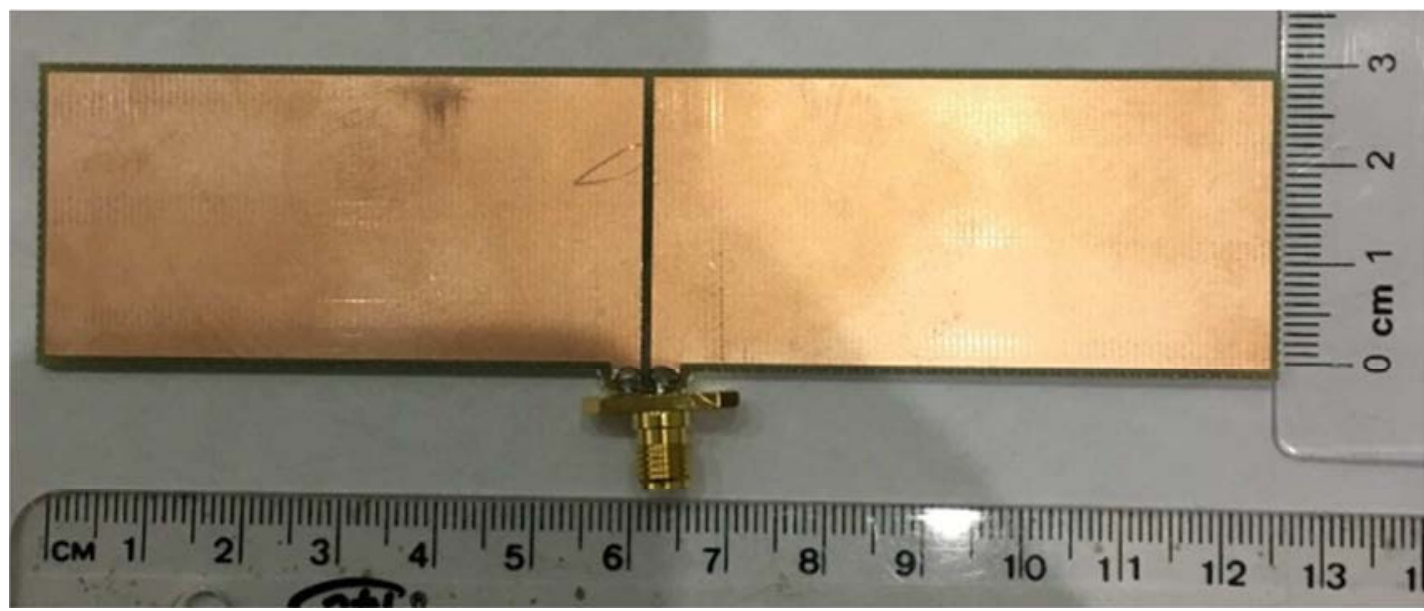

Figure 4. Photography of fabricated traditional type coplanar dipole antenna without slot.

From Figure 5 and Table 3, only dual operating frequency bands can be excited for the traditional type coplanar dipole antenna. From the simulation results described in section 3, it is easily observed that the coplanar dipole antenna with inverted-H slot exhibits more operating frequency bands than the traditional coplanar antenna without slot. We use the same geometric parameters as described in section 3 to fabricate the proposed coplanar dipole slot antenna. Photographs of fabricated coplanar dipole slot antennas with changing L2 and fixing $\mathrm{W} 2=5 \mathrm{~mm}$ and with changing $\mathrm{W} 2$ and fixing L2 $=8.5 \mathrm{~mm}$ are shown in Figures 6 and 7, respectively.

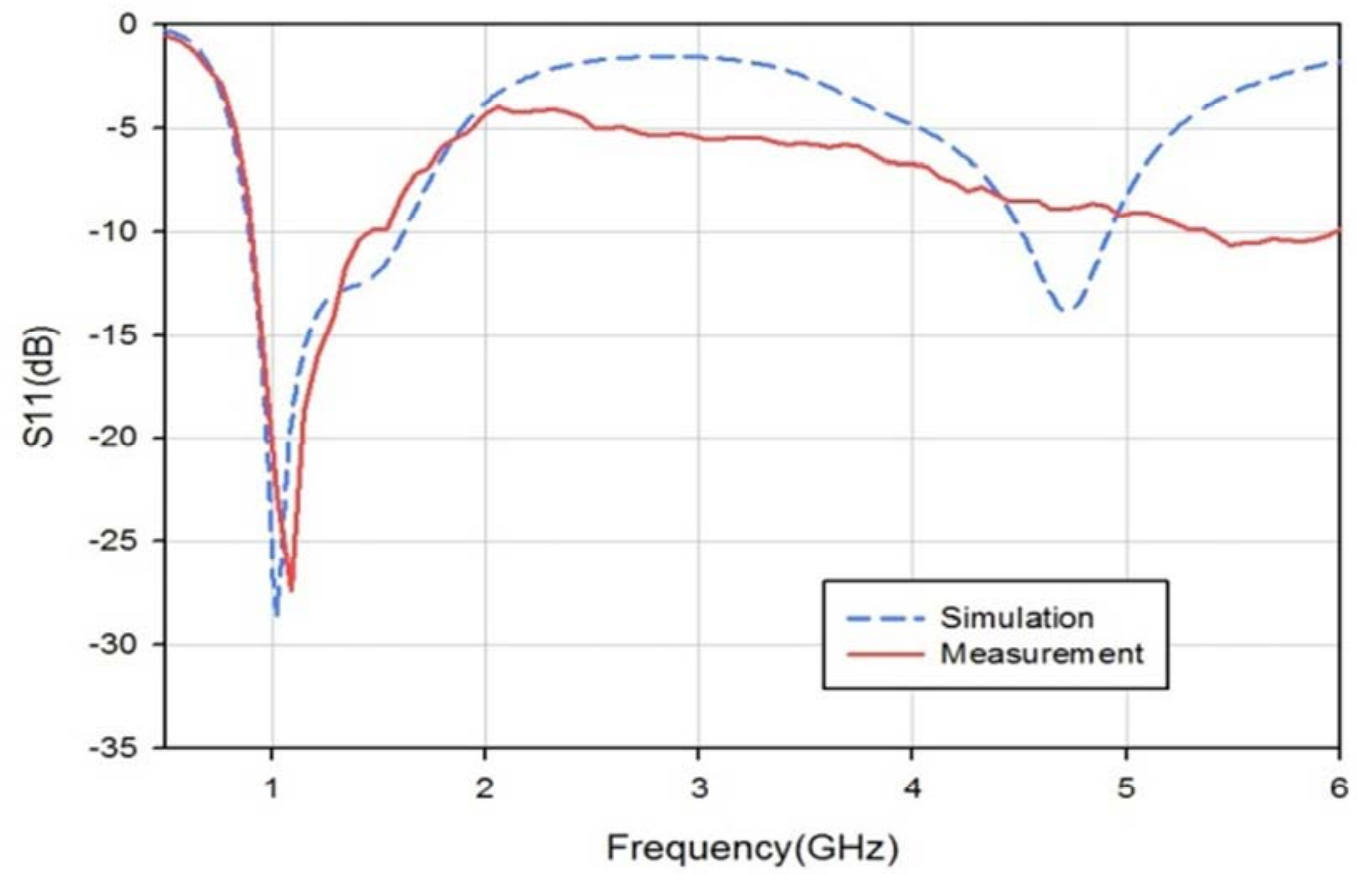

Figure 5. Comparison of simulated and measured $S_{11}$ against frequency of the traditional type coplanar dipole antenna without slot.

Table 3. Simulated and measured results of the traditional type coplanar dipole antenna without slot.

\begin{tabular}{|c|c|c|c|c|}
\hline & $\mathbf{f}_{0}$ & $S_{11}$ & $\mathbf{f}_{1}, \mathbf{f}_{2}$ & BW \\
\hline & (GHz) & (dB) & (GHz) & (GHz) \\
\hline \multirow{3}{*}{ Simulation } & 1.01 & -28.35 & $0.89,1.61$ & 0.72 \\
\hline & 4.71 & -13.81 & $4.51,4.91$ & 0.40 \\
\hline & 1.08 & -27.16 & $0.90,1.45$ & 0.55 \\
\hline Measurement & 5.49 & -10.68 & $5.38,5.98$ & 0.60 \\
\hline
\end{tabular}




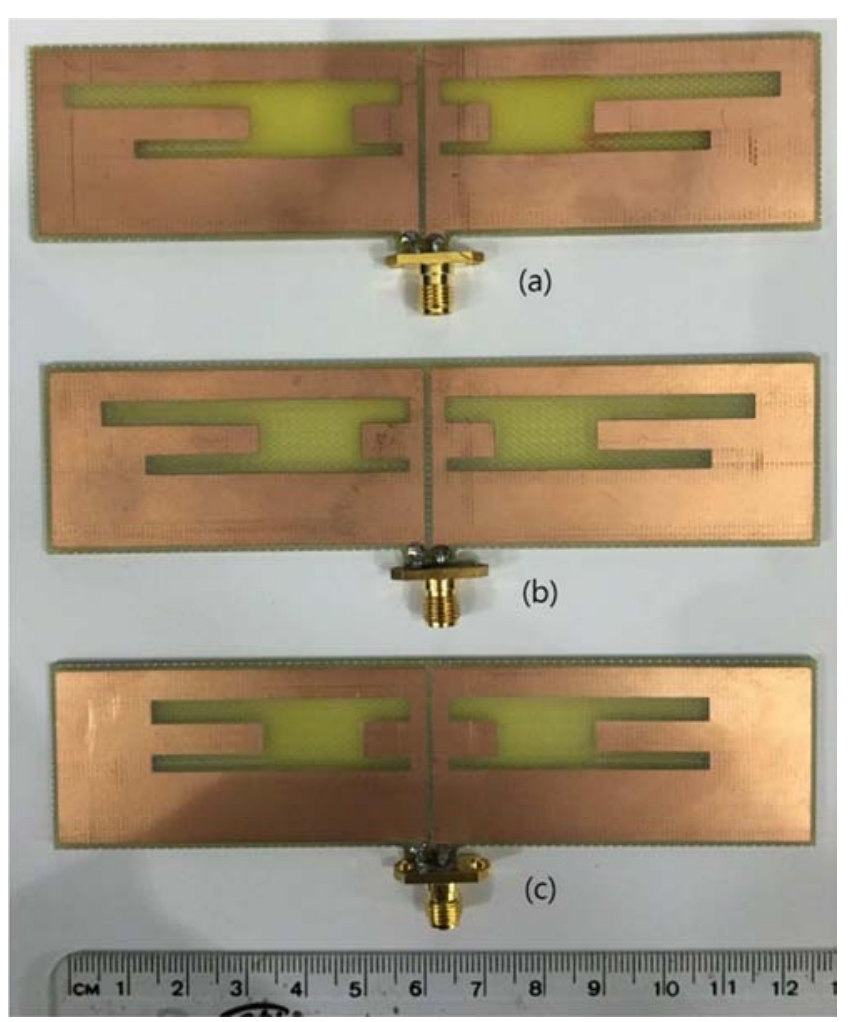

Figure 6. Photography of fabricated coplanar dipole slot antenna with $W 2=5 \mathrm{~mm}$ and (a) $L 2=4.5 \mathrm{~mm}$ (b) $L 2=8.5 \mathrm{~mm}$ (c) $L 2=15.5 \mathrm{~mm}$.

The measured curves of $S_{11}$ against frequency for varying the inverted-H slot parameter L2 of the proposed antenna with $\mathrm{W} 2=5 \mathrm{~mm}$ are shown in Fig.8. The measured results including $\mathrm{f}_{0}, \mathrm{~S}_{11}, \mathrm{f}_{1}, \mathrm{f}_{2}$, and BW are listed in Table 4. From Figure 8 and Table 4, multiple operating frequency bands are also obtained. The measured results show better $S_{11}$ performance than the simulated results which may come from impedance matching phenomenon. Therefore, the measured results appear the additional operating band at $5.88 \mathrm{GHz}$ for the fabricated planar dipole slot antenna with $\mathrm{L} 2=4.5 \mathrm{~mm}$. For the fabricated planar dipole slot antennas, the dual band phenomenon merges into single band at $3.93-5.23 \mathrm{GHz}$ for $\mathrm{L} 2=8.5 \mathrm{~mm}$ and at $4.60-5.92 \mathrm{GHz}$ for $\mathrm{L} 2=15.5 \mathrm{~mm}$. The measured $\mathrm{S}_{11}$ curves are slightly shifted to higher frequency compared with the simulated $\mathrm{S}_{11}$ curves.

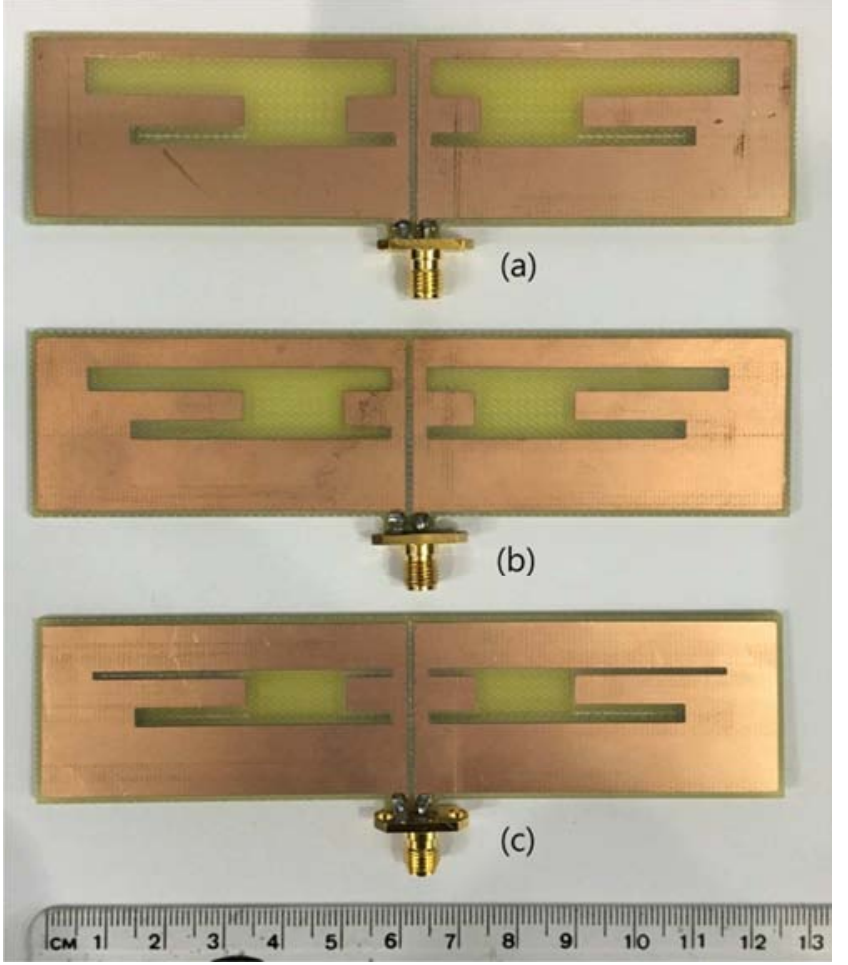

Figure 7. Photography of fabricated coplanar dipole slot antenna with $L 2=8.5 \mathrm{~mm}$ and (a) $\mathrm{W} 2=3 \mathrm{~mm}(\mathrm{~b}) \mathrm{W} 2=5 \mathrm{~mm}$ (c) $\mathrm{W} 2=8 \mathrm{~mm}$.

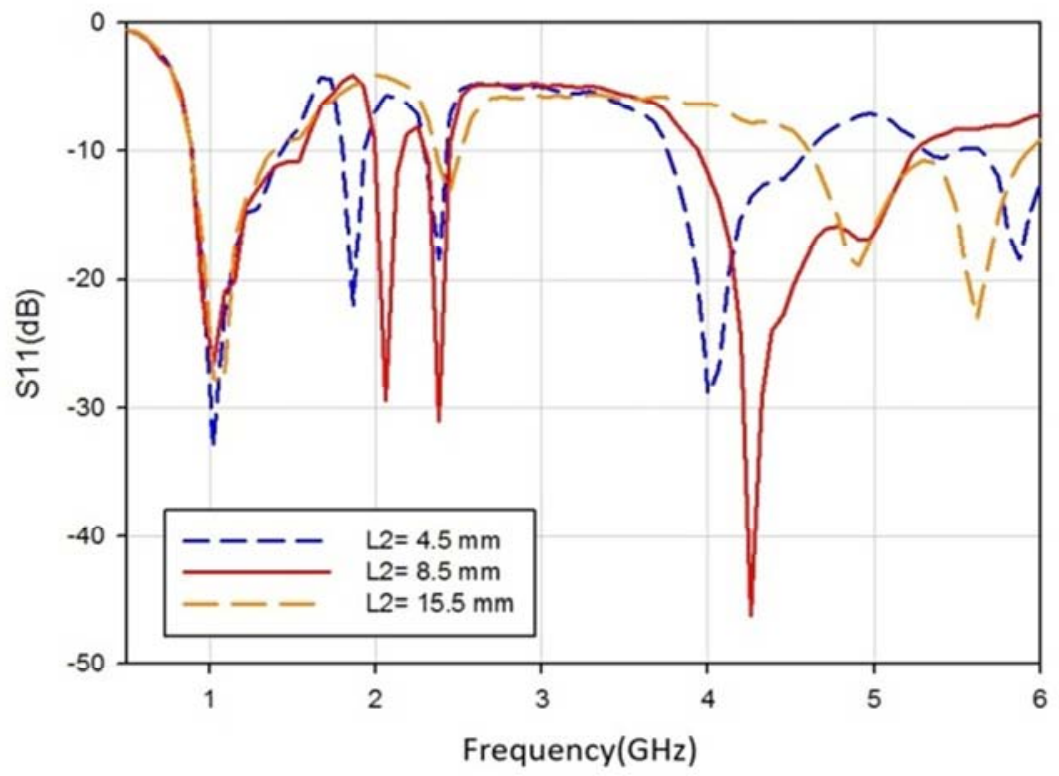

Figure 8. Measured $S_{11}$ against frequency of the fabricated coplanar dipole slot antenna with W2=5mm. 
The measured curves of $\mathrm{S}_{11}$ against frequency for varying the inverted-H slot parameter W2 of the proposed antenna with $\mathrm{L} 2=8.5 \mathrm{~mm}$ are shown in Fig. 9. The measured results are also listed in Table 5. From Figure 9 and Table 5, multiple operating frequency bands are also obtained. At higher frequency band, the merged band phenomenon has also been observed for $\mathrm{W} 2=5 \mathrm{~mm}$ and $\mathrm{W} 2=8 \mathrm{~mm}$ which may come from better impedance matching phenomenon. The measured $\mathrm{S}_{11}$ curves are slightly shifted to higher frequency compared with the simulated $\mathrm{S}_{11}$ curves. The trends of the measured results relate well with the simulated results.

To reach the operating frequencies covering $900 / 1575 \mathrm{MHz}$ and $2.0 / 2.4 / 2.45 / 5.0 \mathrm{GHz}$, the better performance antenna with $\mathrm{L} 2=8.5 \mathrm{~mm}$ and $\mathrm{W} 2=8 \mathrm{~mm}$ is used to study the characteristics of the proposed antenna. The curves of $S_{11}$ against frequency of the simulated and fabricated antenna with $\mathrm{L} 2=8.5 \mathrm{~mm}$ and $\mathrm{W} 2=8 \mathrm{~mm}$ are illustrated in Figure 10 . The simulated and measured results of this proposed antenna are listed in Table 6.

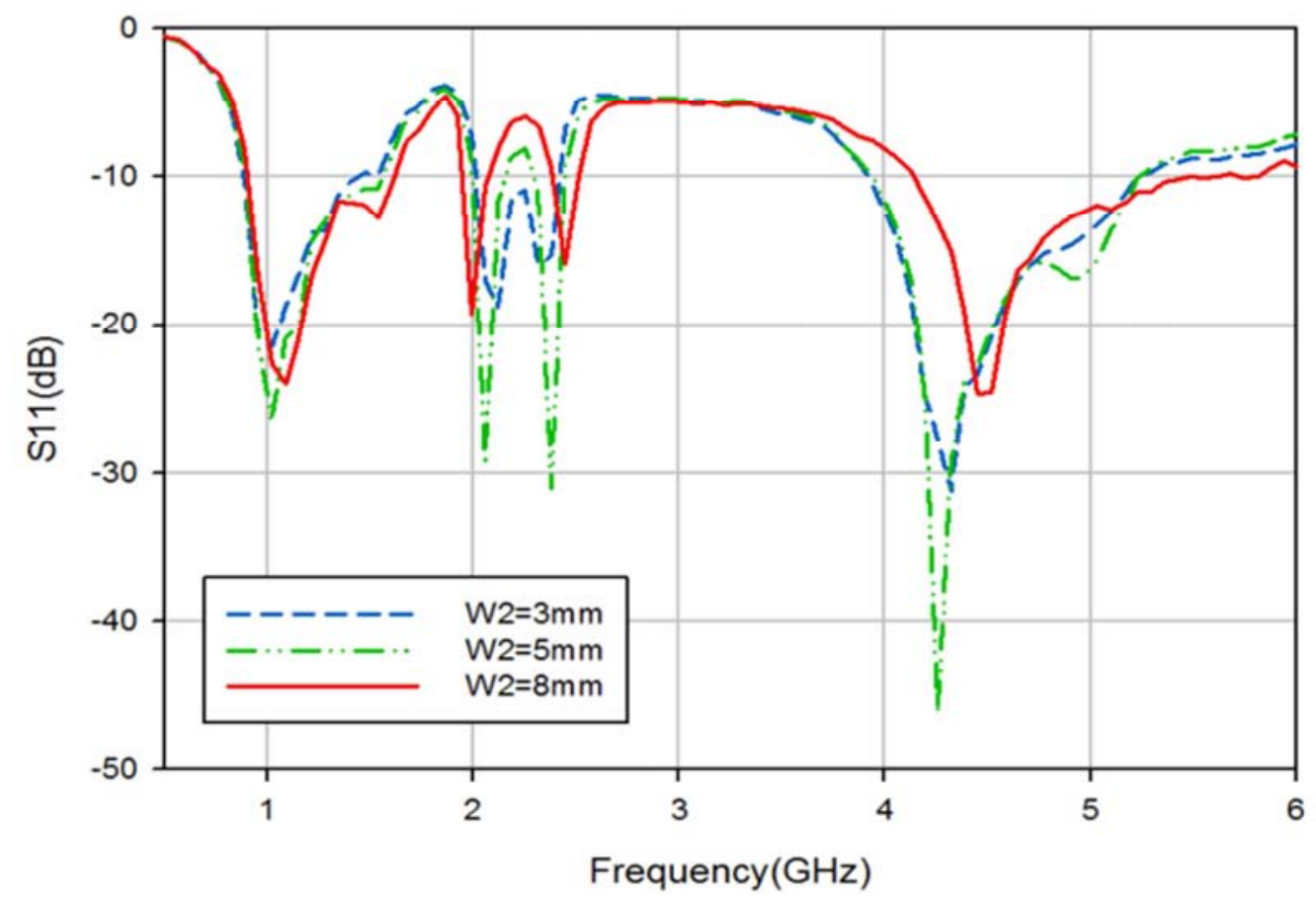

Figure 9. Measured $S_{11}$ against frequency of the fabricated coplanar dipole slot antenna with L2=8.5m.

Table 4. Measured results of the fabricated coplanar dipole slot antenna with $W 2=5 \mathrm{~mm}$.

\begin{tabular}{lllll}
\hline $\mathbf{L 2}$ & $\mathbf{f}_{\mathbf{0}}$ & $\mathbf{S}_{\mathbf{1 1}}$ & $\mathbf{f}_{\mathbf{1}}, \mathbf{f}_{\mathbf{2}}$ & $\mathbf{B W}$ \\
\hline $\mathbf{( m m})$ & $\mathbf{( G H z )}$ & $\mathbf{( d B )}$ & $\mathbf{( G H z )}$ & $\mathbf{( G H z )}$ \\
\hline & 1.01 & -32.4 & $0.89,1.43$ & 0.54 \\
& 1.86 & -21.94 & $1.79,1.93$ & 0.14 \\
4.5 & 2.37 & -17.65 & $2.29,2.42$ & 0.13 \\
& 4.00 & -28.65 & $3.75,4.60$ & 0.85 \\
& 5.88 & -18.27 & $5.63,6.21$ & 0.58 \\
& 1.01 & -26.27 & $0.89,1.56$ & 0.67 \\
& 2.05 & -28.63 & $1.99,2.15$ & 0.16 \\
& 2.38 & -30.77 & $2.29,2.44$ & 0.15 \\
& 4.26 & -44.94 & $3.93,5.23$ & 1.30 \\
& 1.08 & -27.85 & $0.89,1.38$ & 0.49 \\
& 2.44 & -13.18 & $2.36,2.50$ & 0.14 \\
& 5.61 & -23.02 & $4.60,5.92$ & 1.32 \\
\hline
\end{tabular}

From Figure 10 and Table 6, the merged band phenomenon also appears at higher frequency of the fabricated coplanar dipole antenna with $\mathrm{L} 2=8.5 \mathrm{~mm}$ and $\mathrm{W} 2=8 \mathrm{~mm}$. The measured impedance bandwidths of this fabricated antenna show better performance than that in simulation condition. There are discrepancies between the computed and measured results which may occur because of the effect of the coaxial connector soldering process and fabrication tolerance.

Table 5. Measured results of the fabricated coplanar dipole slot antenna with $L 2=8.5 \mathrm{~mm}$.

\begin{tabular}{lllll}
\hline $\mathbf{W} 2$ & $\mathbf{f}_{\mathbf{0}}$ & $\mathbf{S}_{\mathbf{1 1}}$ & $\mathbf{f}_{\mathbf{1}}, \mathbf{f}_{\mathbf{2}}$ & $\mathbf{B W}$ \\
\hline $\mathbf{m m})$ & $\mathbf{( G H z )}$ & $\mathbf{( d B )}$ & $\mathbf{( G H z )}$ & $\mathbf{( G H z )}$ \\
\hline \multirow{3}{*}{3} & 1.00 & -21.36 & $0.88,1.44$ & 0.56 \\
& 2.11 & -18.68 & $2.01,2.42$ & 0.41 \\
& 4.31 & -30.93 & $3.91,5.22$ & 1.31 \\
& 1.01 & -26.27 & $0.89,1.56$ & 0.67 \\
& 2.05 & -28.63 & $1.99,2.15$ & 0.16 \\
& 2.38 & -30.77 & $2.29,2.44$ & 0.15 \\
& 4.26 & -44.94 & $3.93,5.23$ & 1.30 \\
& 1.07 & -23.68 & $0.90,1.61$ & 0.71 \\
& 1.99 & -18.96 & $1.94,2.07$ & 0.13 \\
& 2.45 & -15.07 & $2.38,2.50$ & 0.41 \\
& 4.46 & -24.65 & $4.13,5.47$ & 1.34 \\
\hline
\end{tabular}




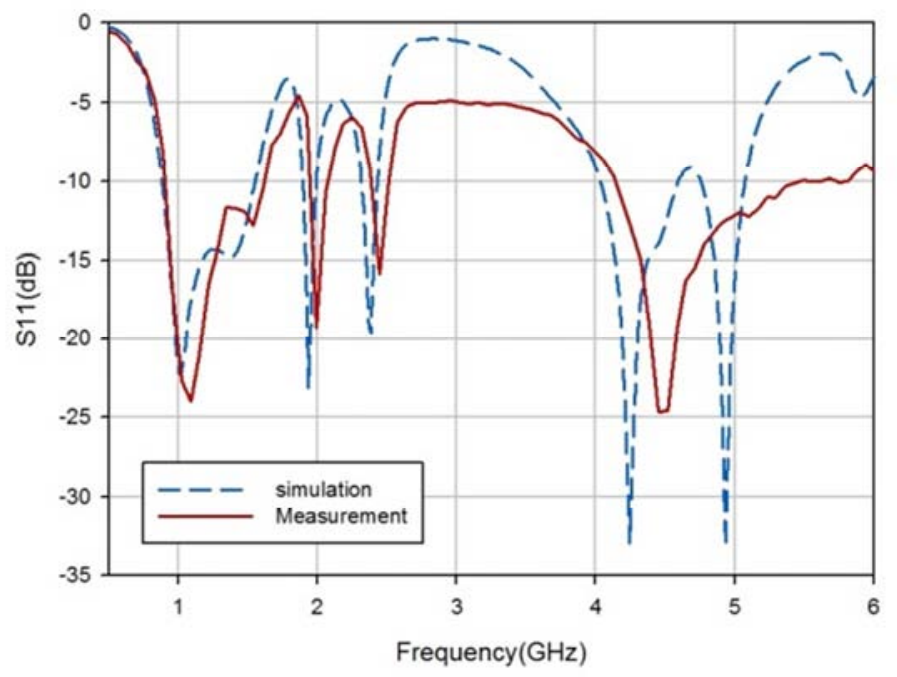

Figure 10. Simulated and measured $S_{11}$ against frequency of the proposed coplanar dipole slot antenna with $L 2=8.5 \mathrm{~mm}$ and $\mathrm{W} 2=8 \mathrm{~mm}$.

Table 6. Simulated and Measured Results of the fabricated coplanar dipole slot antenna with $L 2=8.5 \mathrm{~mm}$ and $W 2=8 \mathrm{~mm}$.

\begin{tabular}{lllll}
\hline & $\mathbf{f}_{\mathbf{0}}$ & $\mathbf{S}_{\mathbf{1 1}}$ & $\mathbf{f}_{\mathbf{1}}, \mathbf{f}_{\mathbf{2}}$ & $\mathbf{B W}$ \\
\hline & $\mathbf{( G H z )}$ & $\mathbf{( d B )}$ & $\mathbf{( G H z )}$ & $\mathbf{( G H z )}$ \\
\hline \multirow{4}{*}{ Simulation } & 1.01 & -22.18 & $0.88,1.55$ & 0.67 \\
& 1.93 & -22.92 & $1.89,1.99$ & 0.10 \\
& 2.38 & -19.55 & $2.31,2.43$ & 0,12 \\
& 4.24 & -32.27 & $4.03,4.59$ & 0.56 \\
& 4.93 & -32.89 & $4.75,5.07$ & 0.32 \\
& 1.07 & -23.68 & $0.90,1.61$ & 0.71 \\
& 1.99 & -18.96 & $1.94,2.07$ & 0.13 \\
& 2.45 & -15.07 & $2.38,2.50$ & 0.41 \\
& 4.46 & -24.65 & $4.13,5.47$ & 1.34 \\
\hline
\end{tabular}

Due to the measured $\mathrm{S}_{11}$ curve shifts to higher frequency, this fabricated antenna with $\mathrm{L} 2=8.5 \mathrm{~mm}$ and $\mathrm{W} 2=8 \mathrm{~mm}$ can be operated at 2.45 RFID system. The measured radiation patterns of this fabricated antenna with $\mathrm{L} 2=8.5 \mathrm{~mm}$ and $\mathrm{W} 2=8 \mathrm{~mm}$ at $0.9 / 1.575 / 2.0 / 2.4 / 2.45 / 5.0 \mathrm{GHz}$ are shown in Figure 11. The measured peak gains for testing frequencies at $\mathrm{X}-\mathrm{z}$ and $\mathrm{y}-\mathrm{z}$ plane of this fabricated antenna are listed in Table
7. From Figure 11, it can be observed that the radiation patterns are almost omnidirectional in the $y-z$ plane. The omnidirectional antenna radiation pattern indicates that the fabricated antenna is good for mobile devices.

\section{Conclusions}

In this study, the fabricated coplanar dipole antenna with inverted-H slot exhibits simple structure and multiband characteristics. The size of inverted-H slot is designed and the frequency bands covering 0.9-1.61 GHz, 1.94-2.07 GHz, 2.38-2.5 GHz, and 4.13-5.47 GHz are obtained. Various designs of inverted-H slot for dipole antenna could perturb the current distribution around the slot and then affect the impedance matching phenomenon. Therefore, carefully choose the designed parameter of the inverted-H slot would implement the suitable antenna that can be used in GPS, RFID, TD-SCDMA, WLAN, public safety application, and 802.11a/802.11ah standard.

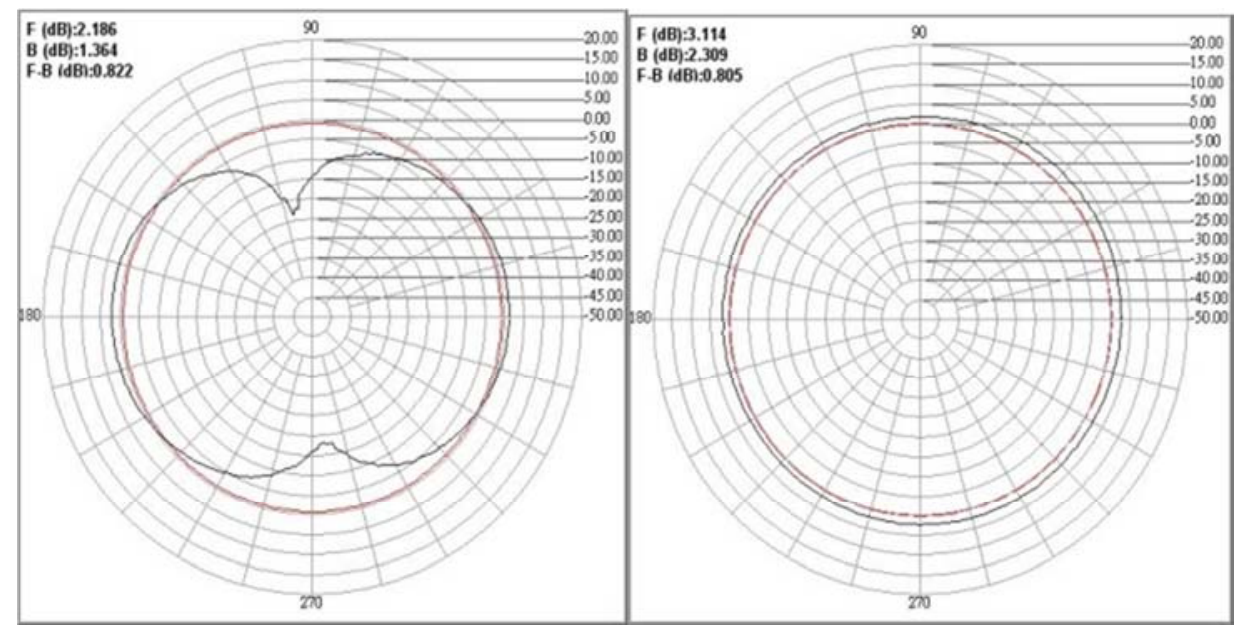

(a) $\mathrm{f}=0.9 \mathrm{GHz} X-\mathrm{Z}$ plane

(b) $\mathrm{f}=0.9 \mathrm{GHz}$ Y-Z plane 


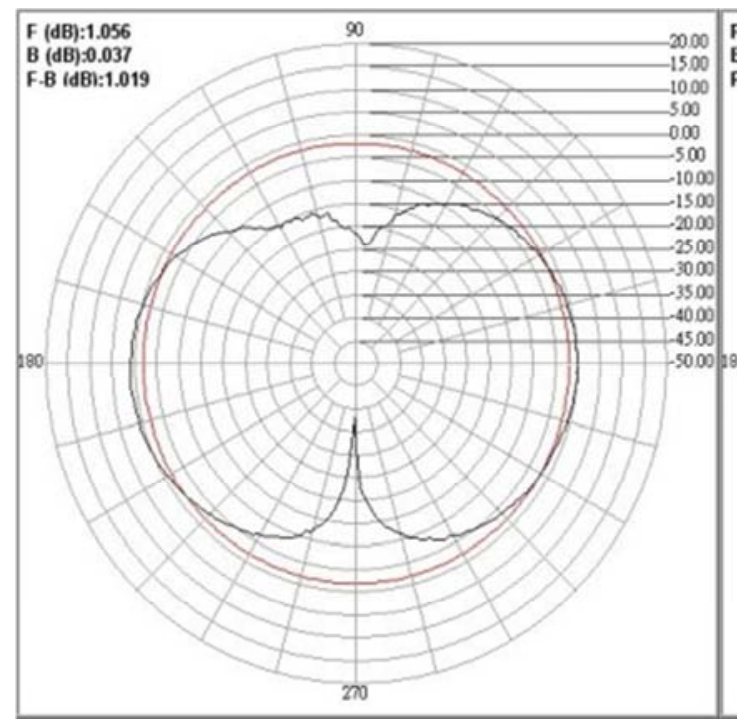

(c) $\mathrm{f}=1.575 \mathrm{GHz} X-\mathrm{Z}$ plane

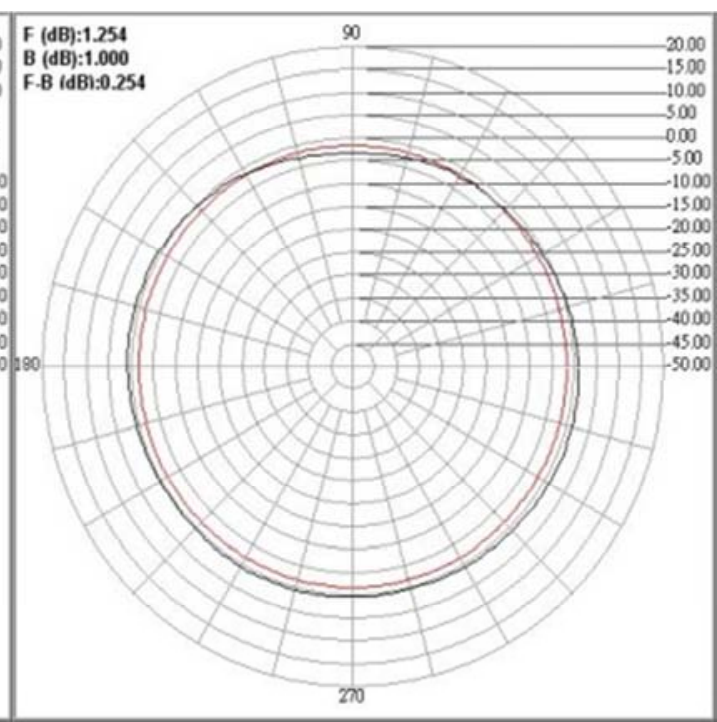

(d) $\mathrm{f}=1.575 \mathrm{GHz}$ Y-Z plane

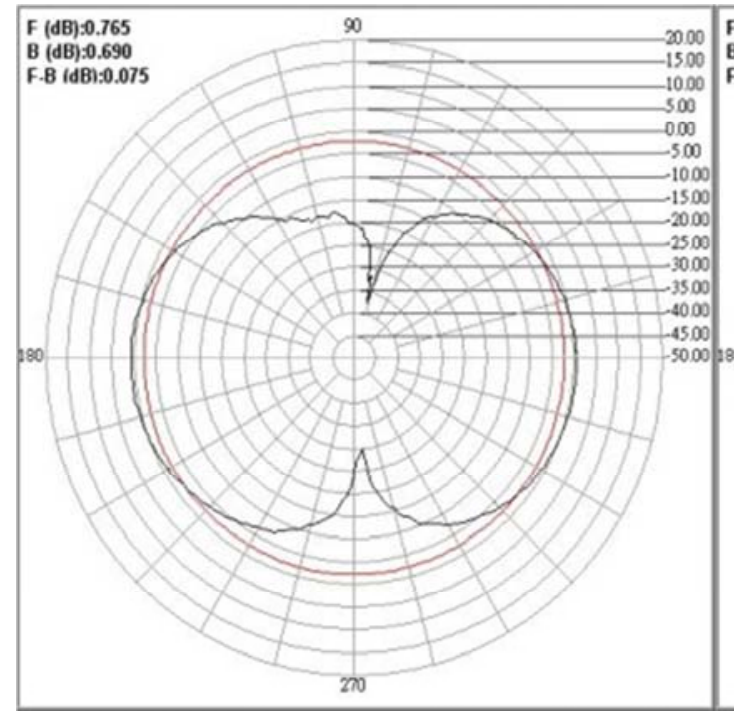

(e) $\mathrm{f}=2.0 \mathrm{GHz} X-\mathrm{Z}$ plane

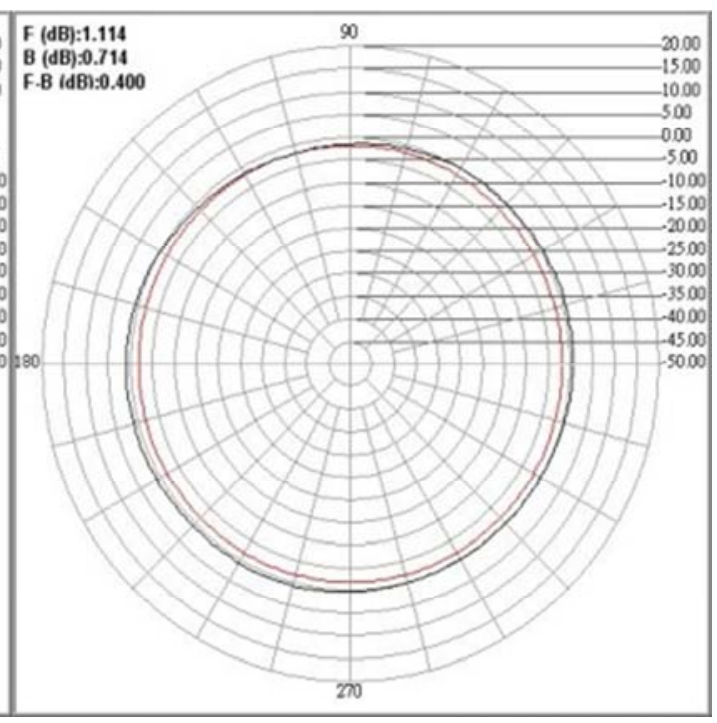

(f) $\mathrm{f}=2.0 \mathrm{GHz}$ Y-Z plane

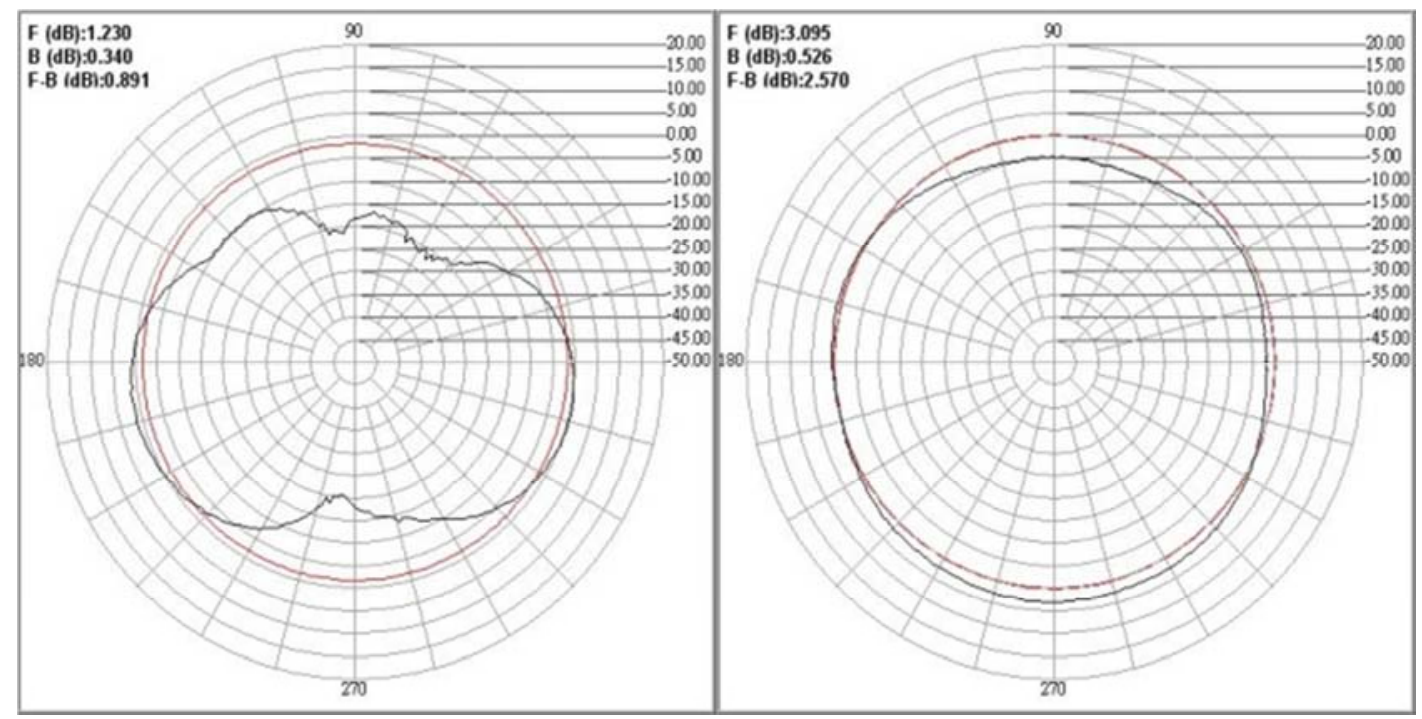

(g) $\mathrm{f}=2.4 \mathrm{GHz} X-\mathrm{Z}$ plane

(h) $\mathrm{f}=2.4 \mathrm{GHz} \mathrm{Y-Z}$ plane 


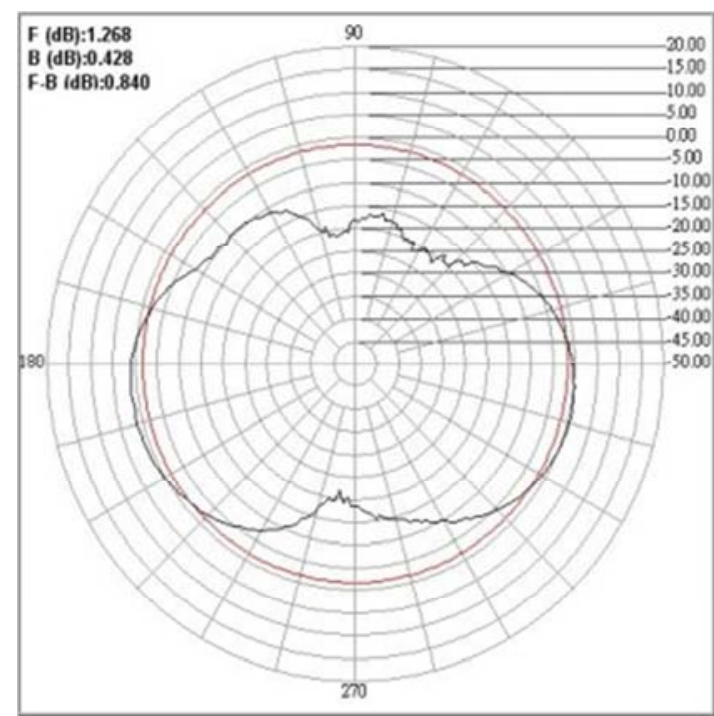

(i) $\mathrm{f}=2.45 \mathrm{GHz} X-\mathrm{Z}$ plane

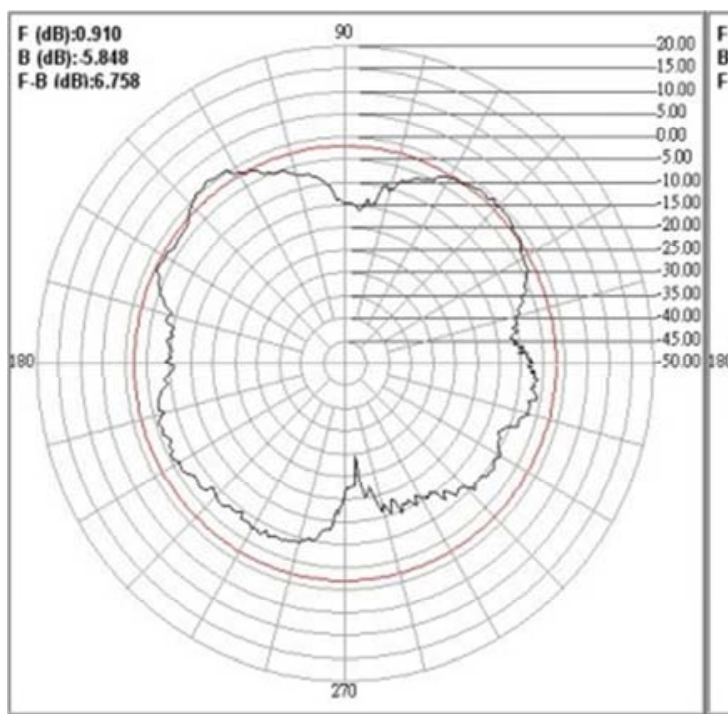

(k) $\mathrm{f}=5.0 \mathrm{GHz} \mathrm{X}-\mathrm{Z}$ plane

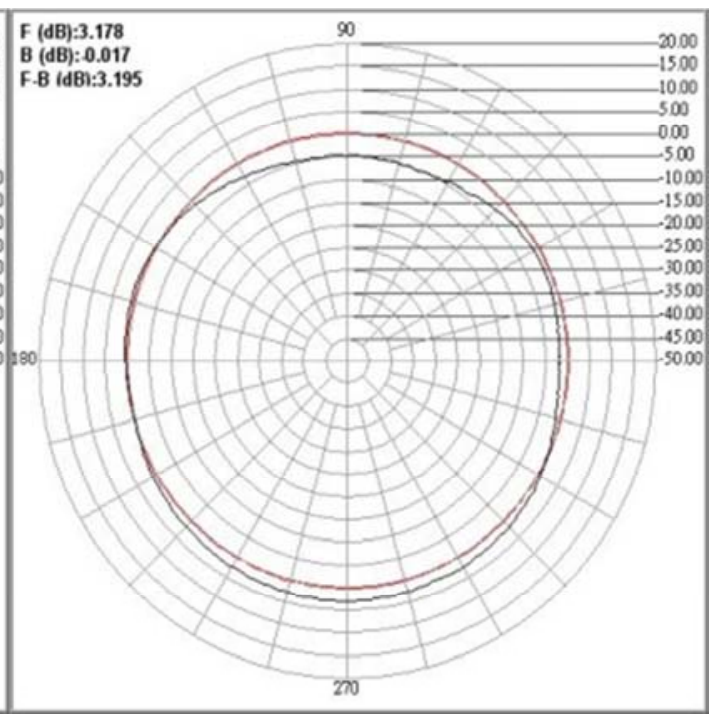

(j) $\mathrm{f}=2.45 \mathrm{GHz}$ Y-Z plane

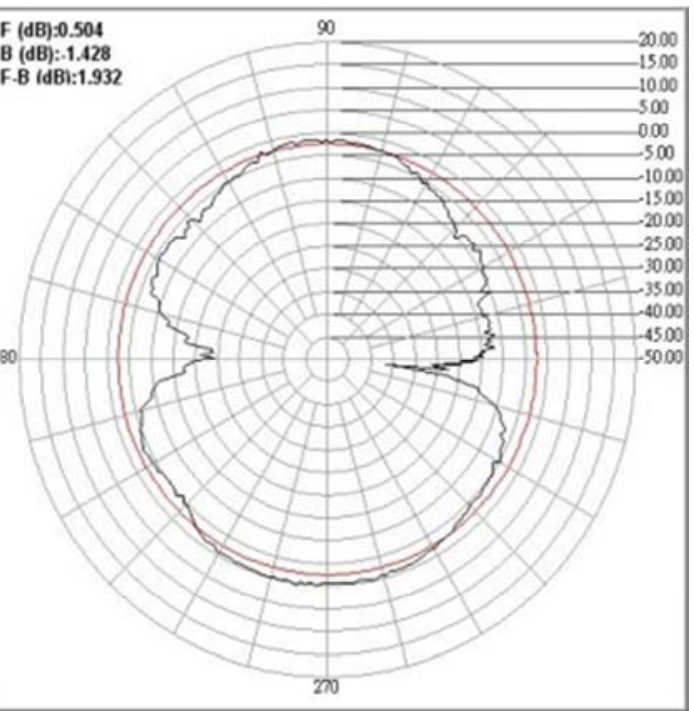

(1) $\mathrm{f}=5.0 \mathrm{GHz} \mathrm{Y}-\mathrm{Z}$ plane

Figure 11. Measured radiation patterns of the fabricated coplanar dipole slot antenna with $L 2=8.5 \mathrm{~mm}$ and $W 2=8 \mathrm{~mm}$.

Table 7. Measured peak gains of the fabricated coplanar dipole slot antenna with $L 2=8.5 \mathrm{~mm}$ and $\mathrm{W} 2=8 \mathrm{~mm}$ at operating frequency.

\begin{tabular}{lll}
\hline Frequency & X-Z plane & Y-Z plane \\
\hline (GHz) & Peak gain $(\mathbf{d B i})$ & Peak gain $(\mathbf{d B i})$ \\
\hline 0.9 & 2.18 & 3.11 \\
1.575 & 1.05 & 1.25 \\
2.0 & 0.76 & 1.11 \\
2.4 & 1.23 & 3.09 \\
2.45 & 1.26 & 3.17 \\
5.0 & 0.91 & 0.50 \\
\hline
\end{tabular}

\section{References}

[1] Wong, K. L., Planar Antennas for Wireless Communications, Hoboken, NJ: Wiley, 2003.

[2] R. K. Raj, M. Joseph, B. Paul, and P. Mohanan, "Compact planar multiband antenna for GPS, DCS, $2.4 / 5.8 \mathrm{GHz}$ WLAN applications" Electronics Letters, vol. 41, 2005, pp. 33-34.
[3] RongLin Li, Bo Pan, Joy Laskar, and Manos M. Tentzeris, “A compact broadband planar antenna for GPS, DCS-1800, IMT-2000, and WLAN applications," IEEE Antennas Wireless Propag. Lett., vol. 6, 2007, pp.25-27.

[4] Y. Y. Lu, S. C. Wei, and H. C. Huang, "Design of RFID antenna for $2.45 \mathrm{GHz}$ applications," Int'l Conf. on Innovative Comp., Information and Control, 2009, pp. 601-604.

[5] H. R. Lee and J. M. Woo, "Asymmetric planar dipole antenna on the surface of conducting plane for RFID tag," Asia Pacific Microwave Conf., 2009, pp.633-636.

[6] J. EL Aoufi, N. Alaoui, M. Essaaidi, M. Benayad, "Design of a low cost planar antenna for $2.45 \mathrm{GHz}$ RFID applications," European Journal of Scientific Research, vol. 61, 2011, pp. 4248.

[7] Y. L. Kuo and K. L. Wong, "Printed double-T monopole antenna for 2.4/5.2 GHz dual band WLAN operations," IEEE Trans. Antennas Propag., vol. 51, 2003, pp. 2187-2192. 
[8] Y. Y. Lu, S. C. Dai, and H. C. Huang, "Design of triple-band planar antenna for LTE/WLAN applications," Int'l Conf. on Intell. Inform. Hiding and Multimedia Signal Proc., 2015, pp. $1-4$.

[9] C. M. Wu, C. N. Chiu, and C. K. Hsu, "A new nonuniform meandered and fork-type grounded antenna for triple-band WLAN applications," IEEE Antennas Wireless Propag. Lett., vol. 5, 2006, pp.346-348.

[10] J. Y. Sze, K. L. Wong, "Bandwidth enhancement of a microstrip-line-fed printed wide-slot antenna," IEEE Trans. Antennas Propag., vol. 49, 2001, pp. 1020-1024.

[11] S. W. Qu, C. Ruan, and B. Z. Wang, "Bandwidth enhancement of wide-slot antenna fed by CPW and microstrip line," IEEE Antennas Wireless Propag. Lett., vol. 5, 2006, pp. 15-17.
[12] C. M. Wu, C. N. Chiu, C. K. Hsu, "A new nonuniform meandered and fork-type grounded antenna for triple-band WLAN applications," IEEE Antennas and Wireless Propag. Lett., vol. 5, 2006, pp. 346-348.

[13] P. Xu, Z. H. Yan, C. Wang, "Multi-band modified fork-shaped monopole antenna with dual L-shaped parasitic plane," Electronics Letters, vol. 47, 2011, pp. 364-365.

[14] Y. Y. Lu, J. Y. Kuo, H. C. Huang, "Design and application of triple-band planar dipole antennas," Journal of Information Hiding and Multimedia Signal Processing, vol.6, 2015, pp. 792-805. 